\title{
OBSERVATORIO
}

\section{EDUCACIÓN Y APRENDIZAJE DE LA INFORMACIÓN Y LA DOCUMENTACIÓN: RAÍCES, DESAFÍOS Y LÍNEAS DE ACCIÓN}

\section{Francisco-Javier García-Marco}

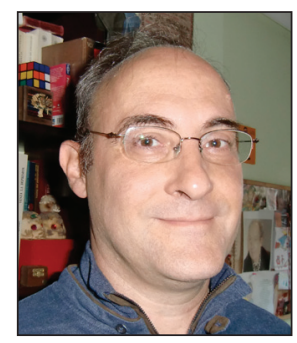

Francisco-Javier García-Marco es doctor en filosofía y letras y catedrático del Área de Biblioteconomía y Documentación de la Universidad de Zaragoza. Dirige la revista Scire y el congreso lbersid desde 1995 y 1996 respectivamente. Ha publicado más de doscientos trabajos relacionados con las aplicaciones de las nuevas tecnologías de la información a la documentación científica, la difusión de la cultura y la gestión social, así como con la teoría de la documentación, el tratamiento y recuperación de la información y lenguajes documentales. Es miembro del Grupo ThinkEPI.

http://orcid.org/0000-0002-6241-4060

Universidad de Zaragoza, Área de Biblioteconomía y Documentación Pedro Cerbuna, 12. 50009 Zaragoza, España jgarcia@unizar.es

\section{Resumen}

Se revisa la evolución de la formación en información y documentación desde las primeras iniciativas sistemáticas de educación profesional hasta nuestros días, enfatizando los últimos veinte años de historia. Seguidamente, se presentan los principales retos y propuestas de acción de cara al futuro: clarificar la misión, el nicho ecológico y los objetivos estratégicos; cuidar el centro y abordar la periferia; cuidar la marca y nuestros públicos objetivos, resituando al estudiante como cliente principal; arbitrar un observatorio permanente que permita programar las enseñanzas desde las necesidades del mercado de trabajo y de los estudiantes; articular adecuadamente los niveles de formación con realismo y en el marco de una formación a lo largo de la vida; reconstruir y perseguir la interdisciplinariedad en el diseño de los estudios; modular la formación tecnológica de acuerdo a los cambios sociales y el perfil del alumnado; y cuidar la calidad operativa y abordar los métodos educativos desde la evidencia. La reflexión se centra en el caso español, pero con una perspectiva internacional.

\section{Palabras clave}

Formación, Educación, Aprendizaje, Ciencia de la información, Biblioteconomía, Archivística, Gestión de la información, Gestión de contenidos, Estudios de información, Prospectiva, Historia, España.

Title: Education and learning about information and documentation: roots, challenges and action lines

\section{Abstract}

The evolution of training and education in information and documentation is reviewed, starting with the first systematic professional education initiatives in the 19th century. Some of the current key challenges and future action lines are discussed: clarifying the mission, the ecological niche and strategic objectives of the discipline; taking care of the disciplinary core and addressing the peripheries; building and looking after the brand and main stakeholders, relocating the student as a prime client; negotiating a permanent observation point to allow the design of curricula based on the labour-market and student needs; programming the educational levels within the framework of life long education; rebuilding and pursuing the interdisciplinary dimension of information studies; modulating technological training according to social changes and student profiles; and ensuring operational quality and addressing the continuous evidence-based improvement of the pedagogical methods. The reflection focuses on the Spanish case, but incorporates an international perspective.

\section{Keywords}

Education, Training, Learning, Information science, Library science, Archival science, Information management, Content management, Information studies, Prospective, History.

García-Marco, Francisco-Javier (2013). "Educación y aprendizaje de la información y la documentación: raíces, desafíos y líneas de acción". El profesional de la información, noviembre-diciembre, v. 22, n. 6, pp. 489-504.

http://dx.doi.org/10.3145/epi.2013.nov.01 


\section{Introducción}

Quiero empezar felicitando a EPI por la oportunidad de este número monográfico, dada la situación actual, revolucionada y revolucionaria, de la educación en el campo de la información y la documentación. Me gusta también su título, que equilibra educación y aprendizaje; y que refleja el conflicto y el encuentro - de todo hay y todo es necesario- entre la formación que viene de fuera - de los cuerpos docentes, profesionales o empresariales - y la que se busca desde el propio sujeto - el aprendizaje-; entre la educación como esfuerzo de comunicación y capacitación, y el aprendizaje como el resultado que, a partir del esfuerzo personal del discente y los docentes - si los hay-, hace posible, al fin y al cabo, la auténtica competencia profesional.

Seguidamente - aunque no resulta en absoluto necesario dada la madurez de los lectores de EPI-, me gustaría insistir de entrada y de forma bien explícita en que las ideas que voy a expresar aquí sólo pueden significar una contribución parcial y sesgada desde un punto de vista personal a un debate amplio que está en la mente de casi todos los que viven vocacionalmente la información y la documentación. Son ideas limitadas, que reflejan lo que pienso en el momento actual desde mi necesariamente parcial estado de conocimiento, sesgado por mis lecturas y experiencias; ideas que lanzo sobre todo con el ánimo de fomentar el debate, con la mirada puesta más en el horizonte que en el pasado, aunque éste constituye el trampolín de mi reflexión. Las he estructurado en dos grandes apartados: 1) ilusiones y realidades, 2) retos y propuestas de acción, con un pivote intermedio dedicado a la revolución digital, dentro de la cual nos encontramos. Así pues, comenzaremos con una revisión de la historia que hemos vivido en estos últimos veinte años y que condiciona nuestro futuro, en ocasiones lastrándonos y en otras impulsándonos; y terminaremos con una recopilación y discusión de retos y posibles líneas de acción más importantes.

\section{Entre la ilusión y la realidad: brevísima historia de la enseñanza de la información y la documentación en España}

La historia de la enseñanza de la información y la documentación en España se puede sintetizar en cuatro grandes fases y cuatro grandes retos:

- la formación de los conservadores capaces de abordar el reto de la conservación del patrimonio documental tras las desamortizaciones;

- la formación de bibliotecarios capaces de promover la democratización de la sociedad;

- la capacitación de técnicos al servicio de la administración moderna, la investigación y la industria; y

- la adaptación a la revolución de la internet, en la que todavía nos encontramos inmersos.

Los objetivos de las sucesivas oleadas no se han perdido, sino que han ido siendo asumidos por las siguientes, aunque lógicamente los énfasis han ido cambiando. Es una historia que ha sido investigada por historiadores muy competentes de nuestro campo ${ }^{1}$.
La primera gran oleada consistió en la formación de los cuadros de funcionarios conservadores del Estado durante la segunda mitad del siglo XIX, creados para hacerse cargo del patrimonio que se pudo conservar del Antiguo Régimen tras las revoluciones liberales y una de sus principales consecuencias, las desamortizaciones. Para ello se creó la Escuela de Diplomática de Madrid, que luego quedaría integrada en la enseñanza universitaria reglada con la fundación de diversas cátedras universitarias, algunas de las cuales intentaron desarrollar sin éxito estudios específicos.

La segunda gran oleada, desde la industrialización a la Guerra Civil, la constituyó la formación de cuadros que apoyaran el desarrollo de las bibliotecas populares — notablemente con la Escuela de Bibliotecarias de Barcelona, la más señera, y la de Navarra-. Es un esfuerzo enmarcado en las políticas sociales de principios de siglo; y especialmente en el noreste de España, orientadas a favorecer la democratización de la educación y la cultura, y favorecer la emancipación y empoderamiento de las clases populares.

La tercera fase está representada por la fundación de las escuelas universitarias de biblioteconomía y documentación $-y$ aquí ya empieza nuestra historia inmediata-. Las nuevas escuelas asumieron la necesidad de formar jóvenes capaces de desarrollar una infraestructura bibliotecaria para el sistema educativo español -entonces en una situación de crecimiento explosivo-, para los servicios públicos culturales y para las crecientes necesidades de los centros de investigación, las empresas y la administración pública en el campo de la gestión de la información. Los estudios de información y documentación se convirtieron así en formales dentro del sistema universitario español, aunque con mucho retraso respecto a los países de nuestro entorno, europeos y americanos.

A pesar de tener su origen en el tardofranquismo, el proyecto de las escuelas universitarias de biblioteconomía y documentación fue asumido incluso con entusiasmo por parte de los cuadros del primer gobierno socialista, pues conectaba también de forma natural con el esfuerzo cultural y educativo de la Segunda República, en el que sentaba las raíces de sus políticas y con las necesidades de sus electores.

Tras el reconocimiento como centro universitario de la Escuela de Barcelona, ligada a la anterior oleada, se aprueba el primer plan de Granada en 1983 fruto de la alianza entre el Departamento de Paleografía y los bibliotecarios de la ciudad. Sus primeros directores fueron significativamente el catedrático del Departamento de Paleografía y Diplomática, José-Ignacio Fernández-de-Viana, y el futuro director de la Biblioteca de Andalucía, Jerónimo Martínez-González. Pronto siguieron con entusiasmo la estela de Barcelona y Granada numerosas universidades españolas, en una historia que es bien conocida.

¿Cuál es la razón del triunfo tan rotundo de las diplomaturas? Son muchas las razones, entre las que se pueden destacar varias, a riesgo de olvidar otras: El país se había desarrollado; las empresas, administraciones y los centros educativos y de investigación necesitaban gestionar una documentación siempre creciente; y parecía que habría 
dinero para acometer nuevas políticas y proyectos. Por otra parte, los estudios se diseñaron fundamentalmente ligados a las humanidades, pero con una perspectiva aplicada que ofrecía nuevas salidas profesionales en un ámbito con demasiados estudiantes y menguantes perspectivas de empleo. Las nuevas titulaciones contaban $a$ priori con un claro apoyo de los gobiernos de la nación -que esperaban de ellas sustento para sus políticas de promoción de la cultura y la educación-, por lo que ofrecían de entrada unas excelentes perspectivas de empleo. Finalmente, incluso representaban una integración entre las políticas del viejo y nuevo régimen, culminando expectativas largamente gestadas dentro del marco del irredento regeneracionismo español.

Sin embargo, las ilusiones pronto se estrellaron contra la dura realidad de una terrible recesión económica - que empezó con la primera crisis del petróleo de 1973-, la cual, lejos de remitir, arreció después de 1979 y se prolongó durante los años ochenta, poniendo en la picota las esperanzas de los felices sesenta. El resultado fue que unas primeras generaciones de diplomados con excelentes expedientes de ingreso y una gran ilusión por el futuro se vieron abocados primero a las listas del paro y luego a un costoso esfuerzo por abrirse camino en el mercado laboral. El enfado inicial, representado por las reivindicaciones de las asociaciones de estudiantes y diplomados en biblioteconomía y documentación, fue dando paso a cierta desilusión; y, a medio plazo, tras el cambio de siglo, sembraría las semillas de la fuerte caída en la demanda de los estudios que ha sido cuidadosamente glosada por Emilio Delgado-López-Cózar, ayudado y seguido por Mercedes De-la-Moneda-Corrochano (Emilio Delgado-López-Cózar, 2002; 2003, 2007ab; Emilio DelgadoLópez-Cózar; De-la-Moneda-Corrochano, 2008; De-la-Moneda-Corrochano, 2012), y que numerosos expertos han seguido con interés (Morales-Sanabria, 2012; Tejada-Artigas, 2013). El fenómeno se ha desarrollado de forma diferente en las distintas autonomías - con mucha mejor situación en Barcelona y Madrid-, pero sólo un notable fracaso en las expectativas de inserción laboral puede explicar, en nuestra modesta opinión, que simplemente el "boca a boca" no haya servido para sostener la matrícula.

En fin, conseguida la consolidación universitaria y a pesar del primer "jaque al rey", los nuevos académicos se concentraron en poner los estudios a la altura de los demás, y asegurar su nicho y sus mecanismos de subsistencia y reproducción dentro del sistema universitario español. Después de una larga lucha de una década - aunque ni de lejos tan larga como la que requirieron las propias diplomaturas-, el objetivo se consiguió finalmente, gracias a la aprobación de la licenciatura de segundo ciclo en Documentación a mediados de los noventa y, casi de forma paralela, de los primeros doctorados, que han dado grandes frutos en los últimos años, animados por el crecimiento del profesorado del área y de sus proyectos de investigación.

La licenciatura abordaba fundamentalmente la formación en gestión - planificación, gestión y evaluación- y en las tecnologías de la información y la comunicación - sistemas, telemática, bases de datos, sistemas expertos-. Intentaba integrar en los estudios los avances tecnológicos de las últimas décadas y la necesidad cada vez mayor en el ejercicio de una gestión profesional, apoyada en el desarrollo de las ciencias de la administración. Sin embargo, a la vez suponía un reconocimiento de que estas cuestiones no estaban convenientemente abordadas en diplomatura.

\section{Un capítulo que sigue abierto: el impacto de la revolución digital}

Justo a mediados de los años noventa se estaba haciendo notar ya de forma incipiente la siguiente oleada de cambios tecnológicos y sociales, que iban a provocar una nueva transformación de los estudios. Los años de implantación de la diplomatura, la licenciatura y el doctorado en documentación contemplaron el desarrollo de la aplicación de las tecnologías de la información y la comunicación, que culminó en la invención de la World Wide Web en 1989, y que, a su vez, desató la popularización y la democratización de la telemática. Precisamente, la licenciatura en Documentación había intentado ya parcialmente abordar esos nuevos retos con suerte desigual, pero la explosión de la World Wide Web cambió completamente las reglas del juego.

El profesorado - de por sí algo desconcertado por la ruptura de sus expectativas respecto a la salida laboral de los estudios, pero con un grupo muy importante esperanzado por la explosión de la "documentación digital" - se partió 


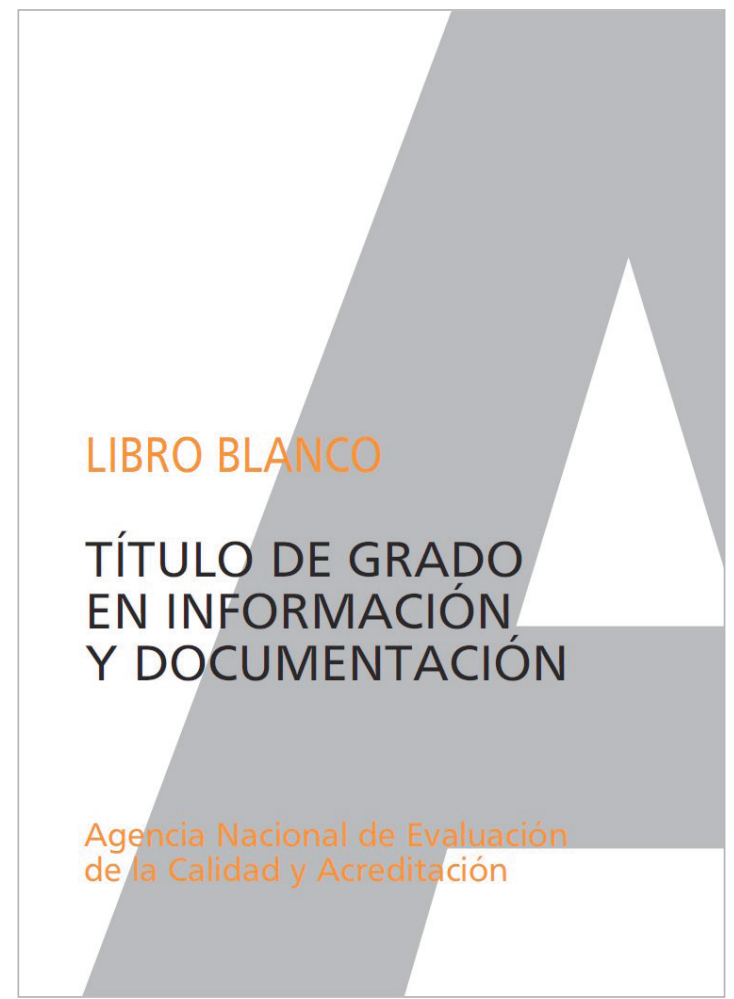

http://www.aneca.es/var/media/150424/libroblanco_jun05_ documentacion.pdf

en la clásica fractura entre "antiguos" y "modernos". Algo parecido pasó entre los profesionales. Muchos creímos que la salida a la crisis de empleo en las bibliotecas, archivos y centros de documentación estaba en la dirección de internet; y nos lanzamos con entusiasmo a seguir la pista.

En la carrera se ha corrido el peligro de arrojar al bebé con el agua de lavarlo, como dicen los anglosajones: muchos, tanto desde dentro de los claustros como desde fuera de ellos, pronosticaban el fin de la catalogación, del control de vocabulario o, incluso, de las propias bibliotecas. Los alumnos -fundamentalmente, procedentes de las humanidadesrecibían mensajes contradictorios en medio de unos planes de estudio que a muchos de ellos no se les ocultaba que se estaban quedando obsoletos. Mientras unos dudaban del futuro de los estudios ante el panorama de cambio, otros echaban las campanas al vuelo, levantando expectativas que tampoco han resultado fundadas.

Casi veinte años después, da la impresión de que el tiempo no ha dado la razón del todo a nadie. Por un lado, a estas alturas está meridianamente claro que vamos hacia un entorno que será muy pronto abrumadoramente digital: primero fue la música, luego el vídeo, los mapas, las revistas científicas, la prensa y ahora los libros; mientras, el patrimonio documental en soporte papel se está digitalizando a marchas forzadas. Los trabajos tradicionales de bibliotecas y archivos se están también automatizando y telematizando a gran velocidad, de tal manera que las nuevas bibliotecas digitales funcionan cada vez con menos concurso de trabajo humano. Quedan -y quedarán - nichos importantes en formato tradicional, notablemente las bibliotecas y archivos con fondos anteriores a la revolución digital, que son muchos; pero que están volcando sus fondos en internet, por lo que su función estará más dirigida a la preservación y al sostén de centros de investigación en ciencias humanas y sociales.

Por el otro lado, ni la catalogación, ni el control de vocabulario, ni las bibliotecas han muerto, como algunos pronosticaban, aunque haya cambiado el lenguaje y ahora se hable de etiquetado, metadatos, esquemas de metadatos, ontologías, repositorios, bibliotecas y curadores digitales. En realidad, la web semántica puede suponer a medio plazo -junto con la integración entre datos y documentos y el desarrollo de agentes automáticos capaces de explotar los nuevos formatos - una inmensa "rebibliotecarización" de la internet -si se me permite el neologismo-, aunque bajo bases y protagonistas nuevos, en un entorno en el debemos ganarnos el sitio en colaboración y competencia con otros profesionales.

Resultado de este nuevo cambio de énfasis en los estudios - primero desde la conservación a los servicios de información, ahora de los servicios de información "tradicionales" a la gestión de la información y a los digitales - ha sido el cambio de marca desde la Biblioteconomía y la Documentación a los estudios en Información y Documentación, que se concretó en el famoso Libro blanco (Agencia, 2004) que luego inspiraría la transformación de la mayoría de los títulos de diplomatura y licenciatura en los de grado. El Libro blanco se gestó por las mismas fechas que cuajaba en Estados Unidos el movimiento de las iSchools. Se trata de un trabajo muy notable que intentaba programar las enseñanzas desde el consenso europeo y que, sin embargo, se ha visto superado muy pronto por los rápidos cambios. Su base fue el Euroreferencial de 1999, que sufrió una revisión mayor precisamente en su nueva edición de 2004 (European Council of Information Associations, 1999, 2004). Por otra parte, el énfasis en los aspectos relacionados con la administración - planificación, implantación, gestión, evaluación, proyectos... - conecta más con el movimiento orientado a la gestión de información que promovió la Federación Internacional de Información y Documentación (FID) y que, en ese sentido, ha conseguido una victoria importante después de su desaparición. En cualquier caso, el Libro blanco, además de la perspectiva europea, ha supuesto un paso de gigante en la incorporación de las demandas de formación de las asociaciones profesionales en los programas académicos, aspecto fundamental en cualquier currículo de la universidad contemporánea.

\section{Está claro que vamos hacia un entorno que será muy pronto abrumadoramente digital}

Este movimiento de transición desde la marca "biblioteca" a la marca "información" que se aprecia en los nuevos grados no es peculiar de España, y también se está produciendo en Iberoamérica (Munera, 2012). En los países nórdicos y anglosajones, el proceso lleva ya muchos años en marcha y ha cuajado en nuevas organizaciones académicas. En muchas 
universidades del norte de Europa, se ha optado por unir los estudios de información y documentación con los de comunicación -también cuestionados por la revolución digitalen una suerte de estudios de información y comunicación; o, en ocasiones, con los de informática. En los sitios donde la facultad estaba más consolidada se ha seguido un camino parecido a las iSchools (Cronin, 2005) ${ }^{3}$, un movimiento nacido en Norteamérica que propugna abrir nuestro campo de forma decidida a la información digital y a las nuevas tecnologías de la comunicación - teléfonos inteligentes, tabletas, información en la web, posicionamiento, gestión de contenidos digitales...-, para intentar inspirar y atraer a la nueva generación de nativos digitales. En España el enfoque en la información y la documentación hemos visto que conecta más con el espíritu de la gestión de la información más que en el cambio digital; lo cual, paradójicamente, le proporciona un toque "retro" respecto al movimiento de los iStudies, que debe hacernos reflexionar de cara al futuro próximo, ya que los estudiantes y empleadores del futuro van más en esta última línea, sin descuidar sus grandes aportaciones.

Además, durante lo que llevamos de nuevo siglo, la necesidad de seguir el paso a la revolución digital se ha retroalimentado con otros dos procesos que han favorecido un proceso de rápido cambio en las titulaciones: la crisis en los números de estudiantes de nuevo ingreso y la implantación de las reformas previstas en el Espacio Europeo de Educación Superior (EEES). Respecto al primero, ya con el cambio de siglo se empezó a apreciar que el ingreso en la diplomatura se había estancado y al poco se pudo ver que empezaba a descender. Como se desprende de la bibliografía, la preocupación se aprecia en el número de artículos sobre el mercado de trabajo que tiene su pico en los años 2000-2003. A partir de 2007 crece el número de notas cortas, pero se estanca la publicación de los estudios en profundidad en relación con el impacto de la crisis, el terrible paro juvenil que estamos sufriendo y quizá debido a la renuencia a ofrecer resultados descorazonadores. A pesar de ello, la entrada de estudiantes en la licenciatura, deseosos de alcanzar dicho nivel o reciclar sus habilidades, y la adaptación a las directrices de Bolonia, con un mayor número de optativas y menor ratio profesor alumno amortiguaron durante gran parte de la primera década del nuevo siglo los efectos del problema. En los próximos años, el problema, como veremos, amenaza con convertirse en un reto crucial.

Se plantea la eliminación de las titulaciones que estén por debajo de los 50 alumnos de nuevo ingreso

En lo que concierne al segundo proceso, en nuestra área de conocimiento los objetivos del EEES están en buena parte conseguidos 0 , al menos, bien encaminados: los planes de estudio actuales se programan de acuerdo con el análisis de competencias; son mucho más prácticos; las metodologías docentes son notablemente activas, orientadas a proyectos y colaborativas; $y$ tienen en cuenta el esfuerzo del estudiante (el famoso crédito europeo). Este esfuerzo - aunque quede

European Council of Information Associations (ECIA)

Euroreferencial en

Información y Documentación VOLUMEN I

Competencias y aptitudes de los Profesionales europeos de información y documentación

El Euroreferencial de 2004 fue traducido al español por Carlos Tejada-Artigas y publicado por Sedic

trabajo por hacer y no quepa dormirse en los laureles- es probablemente uno de los grandes activos de los académicos y profesionales del área. Por otra parte, no es flor de un lustro, sino que la preocupación por los aspectos docentes ha sido una constante en nuestra disciplina, aunque ciertamente se ha visto reforzada en el marco del proyecto por incorporarse al EEES no sólo en los aspectos formales, sino en los métodos. Hitos señalados han sido, entre otros, la celebración en 1993 en Barcelona del Segon seminari internacional de docència bibliotecària; en 1997, del congreso sobre Métodos didácticos en Biblioteconomía y Documentación en Madrid (Martínez-Comeche, 1997); en 2008, del evento monográfico en Salamanca sobre Formación, investigación y mercado laboral en información y documentación en España y Portugal (Frías; Travieso, 2008); o la publicación del monográfico coordinado por Fuentes-Pujol (2011). Los trabajos publicados en ellos y en otros congresos y revistas muestran la cantidad y calidad de los esfuerzos realizados. Además de las investigaciones orientadas a la programación basada en competencias genéricas y factores motivacionales (García-Marco, 2010), destacan las investigaciones sobre el uso de tecnologías educativas, como los portales y recursos digitales (Pinto, 2011; 2012), Wikipedia (Saorín-Pérez; Haro; Pastor, 2011) y las redes sociales (Arguimbau; Ribera; Fuentes-Pujol, 2011). Sin embargo, queda camino para avanzar, y es necesario evitar caer en triunfalismos, denigrar el trabajo anterior o dar por terminada la tarea (Faba-Pérez; Rico-Collado, 2012).

En muchos aspectos, la docena de años que se sitúa entre el despegue de la World Wide Web y la crisis de 2007 fue una época dorada para la profesión. Hubo una gran actividad en congresos, cursos y publicaciones; y el empleo mejoró no- 
tablemente, aunque gran parte de esos puestos de trabajo tuvieran un carácter precario o de baja remuneración (Tejada-Artigas, 2002; Moreiro-González; Tejada-Artigas, 2003; Tejada-Artigas; Rodríguez-Yunta, 2007).

El último lustro, sin embargo, ha quedado finalmente marcado por el estallido de la crisis de deuda española en 2007 y el plan de estabilización subsiguiente, que han convertido la caída en el número de estudiantes de nuevo ingreso en un problema urgente también para los docentes; pues las plantillas de profesorado se están redimensionando rápidamente de acuerdo a las ratios de alumnos, e incluso se plantea a nivel nacional la eliminación de las titulaciones que estén por debajo de cincuenta alumnos de nuevo ingreso, en cuyo entorno o por debajo de él se encuentra más de la mitad de los grados existentes, según muestran datos muy recientes aportados en este mismo número (Ortiz-Repiso;

Calzada-Prado; Aportela-Rodríguez, 2013). Es cierto que los estudios que se han ido realizado apuntan a una crisis de crecimiento y al desajuste de los currículos (García-Marco, 2008; Morales-Sanabria, 2012) y posterior estabilización en cifras homologables con nuestro entorno (De-la-MonedaCorrochano, 2012; Tejada-Artigas, 2013)², pero si la situación no cambia pronto un número muy importante de universidades del país que ofrecen el grado podrían perderlo.

Así pues, podríamos concluir afirmando que los campos científico y profesional de la información y la documentación se han beneficiado enormemente de la segunda ola de revolución telemática. Sin embargo, ahora toca resituarse en una nueva realidad, en la que las tecnologías de la información y la comunicación permean cada vez mayor parte de la vida social; y en la que, más que proporcionarnos viento en las velas, el énfasis exclusivo en la tecnología puede contribuir a disolver nuestros esfuerzos en la marea de la sociedad del conocimiento.

\section{Retos y líneas de acción}

En fin, está claro que la situación mundial de la disciplina ha sido y es de continua reconstrucción en sus límites, alianzas e instituciones. En este sentido, la información y la documentación no constituye una disciplina sólida como la medicina o el derecho, sino un ámbito todavía en construcción, que mantiene fronteras difusas con un gran número de ciencias y profesionales externos, entre los que destacan los comunicólogos y los informáticos.

A este reto global, se suma en nuestro país otro de carácter local que resulta de nuestra situación específica. En España atravesamos un período de crisis de consolidación de los estudios, después de que un crecimiento muy intenso y acelerado se haya revelado insostenible, una especie de "burbuja" que se inserta dentro del proceso general que ha vivido España en los últimos años.

¿Cómo abordar todo esto? He intentado organizar las líneas de acción partiendo de los tres niveles en los que creo se puede y debe actuar: el estratégico - la definición y desarrollo de la misión y el nicho de la disciplina a nivel tanto global como local-; el diseño de los estudios, las infraestructuras y las metodologías docentes; y el operativo -acompañamiento de los estudiantes, etc. Desde el punto de vista del proceso educativo, creo que es útil abordarlo de forma sistémica: el ingreso, el proceso educativo, el egreso $y$, sobre todo, el impacto a corto, medio y largo plazo en los estudiantes, los profesores y el entorno. Vamos a analizar a continuación algunos de los puntos que, ayudado de las opiniones de los expertos, he podido ver más claramente, de una manera que intenta seguir el orden indicado, aunque las interacciones son muchas.

\section{Clarificar la misión, el nicho ecológico y los objeti- vos estratégicos}

El primer reto de los estudios de información y documentación es establecer claramente su misión y los objetivos estratégicos de cara al siglo XXI. Para ello, hemos de estar atentos tanto a los aspectos internos - fortalezas y debilidades - como a los externos - las oportunidades que se nos ofrecen y los peligros que proceden de nuestros competidores.

La definición de la misión y del nicho de la disciplina y la profesión dentro de la ecología de las ciencias y las profesiones se puede y debe abordar tanto de forma teórica -intentando sistematizar su dominio, métodos y principios en relación con las otras ciencias - como empírica - estudiando qué investigan realmente los científicos de la información y, lo que nos importa más ahora, en qué trabajan. Vamos a tratar en este punto el primer abordaje, y dejaremos para el siguiente punto el segundo.

Creo que se debe trabajar la construcción teórica de la disciplina en conexión con la naciente interdisciplina de la ciencia de la información (García-Marco, 2010). La explosión de la información ha provocado el surgimiento de un espacio transdisciplinar de la información dentro del cual los académicos y profesionales del área de Biblioteconomía y Documentación debemos resituarnos y acomodarnos en los próximos años. Desde este punto de vista, podemos modelar el ecosistema de nuestros estudios mediante tres anillos concéntricos: la comprensión de la realidad a través del concepto de información (science of information), el espacio específico de la vida social como preservación e intercambio de conocimiento (social information science) y la inserción e invención de las tecnologías en el marco de las unidades sociales especializadas en esas funciones ${ }^{4}$.

Este último espacio es el que constituye nuestro ecosistema científico y profesional más inmediato. Sin embargo, no estamos en él solos: lo compartimos con profesionales de muy diferente formación y enfoque, desde las disciplinas técnicas, a la gestión, pasando por el control y diseminación de la información en los diferentes ámbitos de la vida humana -las ciencias, las industrias, etc. Dentro de él, lo más propio de la información y la documentación sería su énfasis en la preservación, recuperación y diseminación de los objetos de la memoria personal y social, cada vez más complejos y tecnologizados. Por otra parte, si atendemos a los dos campos específicos más cercanos a los nuestros y más consolidados profesional y científicamente, y que se podrían considerar como competidores, se puede apreciar que, en realidad se centran también en su propio nicho: la informática, en el diseño de sistemas y su optimización en entornos de negocio; las ciencias de la comunicación, en 
proporcionar información para la actualidad -en términos cognitivos, para los procesos de atención-.

El reto a nivel mundial es consolidar una disciplina bien conectada con el resto de las ciencias, pero que tampoco quede desdibujada, alejada de sus nichos principales de empleo, y sometida a un proceso de bandazos, desgaste y finalmente absorción por otros campos más poderosos. Por un lado, debemos colaborar y estar al día en la construcción del nuevo ámbito científico de la ciencia de la información; y, por el otro, asegurar el desbroce y cultivo de un nicho de mercado propio para los profesionales de la documentación, que sustente la disciplina y la profesión. Paralelamente, es necesario construir un discurso integrado y común a lo largo de las diferentes especialidades y disciplinas que forman lo que en España se conoce a veces como Ciencias de la Documentación. Este aspecto es vital para consolidar una disciplina tan amplia y fraccionada, $y$, por ello, tan frágil ante envites externos.

En fin, aunque la actualización tecnológica es fundamental, no lo es todo. Durante los últimos quince años, debido a la urgencia del cambio tecnológico, se han confundido los medios con los fines, cuando son éstos últimos los que dan sentido a nuestro esfuerzo. Sin despreciarlas en absoluto, no creo que las tecnologías de la información y la comunicación, o más específicamente la internet, vayan a ser la solución a la crisis de los estudios, sino la necesidad objetiva de administrar personal y socialmente la información y la memoria. Si de internet y nuevas tecnologías se trata, hay muchos y mejor preparados que están en ese negocio, todo hay que decirlo. Sin embargo, la misión propia de bibliotecarios y archiveros permanece, aunque apoyada en nuevas tecnologías y formas organizativas. La apertura interdisciplinar no puede conllevar un descuido de la propia sistematicidad de la ciencia de la información; de otra manera se puede correr el peligro de incluso quedar desdibujados y desaparecer como disciplina autónoma (Cronin, 2012). Pero esto tampoco debe significar un descuido de las tecnologías, lo que quiero decir - por utilizar una vieja heurística - es que la misión es el contenido y las tecnologías son parte de la forma de la que, ciertamente, tenemos que embebernos completa y actualmente.

\section{Cuidar el centro y abordar la periferia}

Sobre el análisis empírico de la profesión, existe un buen número de estudios realizados específicamente sobre el mercado de trabajo español ${ }^{3}$. El más reciente es el de Abadal, Borrego y Serra (2013), que, aunque está circunscrito a la información del Servei d'Informació d'Ofertes de Feina (SIOF) de la Facultat de Biblioteconomia i Documentació de la Universitat de Barcelona ${ }^{5}$, ofrece resultados muy interesantes por ser una de las facultades señeras en nuestro país y porque analiza sobre todo ofertas de trabajo que son en un $92,4 \%$ contratos laborales. El estudio muestra un equili- brio casi paritario entre la oferta pública y privada; y evidencia que los empleos tradicionales han bajado entre el 2009 y el 2012 del 74,6 al 30,9\%. Observa un enorme crecimiento de los perfiles relacionados con el márketing y comunicación en las redes sociales - del 5,9 al 32,7\%-y la gestión de contenidos digitales 6,5 al 25,7\%. Creo que sería erróneo extrapolar estas cifras totalmente en relación a los nichos tradicionales de empleo - pues el empleo público está congelado desde el inicio del plan de estabilización-. Sin embargo, los números absolutos en el crecimiento de las nuevas profesiones ligadas a los nuevos medios suponen una multiplicación por 9 y 6,5 de los contingentes en apenas dos años. Estas necesidades existen también en el empleo público latente, y los currículos se deberían actualizar de forma muy notable para incorporar las nuevas competencias.

El núcleo principal del empleo - entorno al 40\%- sigue estando en las bibliotecas, centros de documentación y archivos, aunque, como hemos dicho, asumiendo las nuevas necesidades. Los estudios de nicho, especialmente en el campo de las bibliotecas públicas, las universitarias y los centros de documentación, los archivos y la gestión de documentos disfrutan de un empleo reducido, pero estable; a la espera del fruto que sin duda dará el esfuerzo que se está produciendo a nivel internacional en el campo normativo. Es necesario atender con rigor y calidad a estos núcleos de empleo.

Dentro del núcleo principal existen también funciones que necesitan desarrollo. En primer lugar, es necesario afrontar de forma realista el tema de las bibliotecas escolares, probablemente a través de estudios conjuntos con los departamentos de educación, como un área interdisciplinar (Varela, 2013). A día de hoy es uno de los grandes fracasos de la disciplina, y quizá sería mejor aspirar a un poco y conseguirlo, que defender posiciones maximalistas que sólo se pueden abrir camino, hoy por hoy en España, con una partida presupuestaria del Estado que la crisis aleja y que el énfasis en internet hace casi imposible. 
También cerca del centro, y cobrando creciente importancia en el marco de la reorganización del trabajo en las bibliotecas que ha propiciado la automatización, está el desarrollo de competencias informacionales, coloquialmente conocido como 'alfabetización informacional'. Se trata de trasladar la mediación desde la búsqueda a la formación del usuario, aprovechando que la recuperación de información es hoy una actividad generalizada y una competencia básica. El campo del desarrollo de las competencias informacionales ofrece grandes posibilidades porque se puede abordar en todos los niveles y modalidades educativas, desde la educación infantil al doctorado, y, por supuesto, en ámbitos especializados y en la educación permanente. En este caso la frontera se sitúa también con el mundo educativo. En la medida en que los profesionales de los centros de documentación, bibliotecas y archivos se centren más en la provisión de servicios de proximidad dentro de la emergente red mundial de información altamente automatizada y dirigida por grandes gigantes como Thomson Reuters, Reed Elsevier, Google, Amazon o Apple-, la función de atención al usuario se volverá más importante (García-Marco, 2011bc); y de hecho esto está pasando ya.

Hemos de aclararnos sobre si queremos estudiantes de humanidades, de sociales, de tecnología o de cualquier cosa, en qué medida, $y$, sobre todo, cómo arbitrar el tránsito sin estrellarnos nosotros ni sacrificarlos a ellos

En la periferia, la gestión de contenidos ofrece grandes posibilidades de futuro. El problema de esta propuesta es que la gestión de contenidos, al menos en España, está quedando más bien del lado de la ingeniería informática. Aunque es un tema que requiere cuidadosa investigación en muchas universidades, el grueso de los alumnos de Biblioteconomía y Documentación se reclutan en los bachilleratos de Humanidades y Ciencias Sociales, y estos estudiantes están mayoritariamente interesados en su gran parte por el mundo del libro, los documentos, las bibliotecas y los archivos, y raramente por los sistemas de información, que parecen a una persona de dieciocho años cuestión de la ingeniería informática.

La gestión de contenidos aparece como un campo atractivo, pero en el que hay que competir y colaborar con los profesionales de la informática, y esperar que cada grupo vaya encontrando su lugar, que, por la naturaleza del campo, difícilmente será estable. Por otra parte, la gestión de contenidos se está volviendo un campo muy amplio que abarca todo tipo de objetos digitales: mapas, bibliotecas de datos, sistemas de información geográfica, etc. Está dejando de estar circunscrita al documento, y uniéndose al mundo de la gestión de los datos (García-Marco, 2011bc). Desde el punto de vista de la información y documentación, la gestión de contenidos se puede dividir en dos grandes partes: la difusión de información y la organización, preservación y recuperación de los datos y los objetos digitales.
Otro campo muy prometedor ligado al creciente desarrollo de la web social es el trabajo de animar y estructurar redes sociales, cada vez más importantes en todos los sectores de la actividad social y económica. Se trata de los community managers o gestores de comunidades, un entorno que requiere inteligencia humana para sintetizar, organizar, recopilar, organizar, posicionar y comunicar información, y, que, por lo tanto, constituye no sólo un campo de actividad cada vez más importante, sino un nicho de empleo. Este campo, sin embargo, está siendo también abordado por especialistas en marketing y comunicación, con los que se debe convivir.

Otra periferia importante es la gestión del conocimiento, esto es, asegurar que el conocimiento de las personas es documentado y se transfiere luego de nuevo a las personas, apoyando todo el ciclo mediante la gestión de la información. Es también un campo interdisciplinar, pero podemos y debemos encontrar nuestro lugar en él.

También el sector editorial constituye un horizonte muy importante. Está claro que el mundo del comercio del libro ha entrado en crisis y en un periodo de reconfiguración radical, que se va a llevar a muchos queridos agentes por delante; pero también que el aumento de la producción de documentos digitales exige de un nutrido cuerpo de profesionales que apoye el proceso desde el punto de vista de la gestión de la información.

Creo, sin embargo, que en estos campos es importante ser muy realistas. Se trata de áreas de actividad a las que están de hecho optando muchas categorías de profesionales, con fronteras disciplinares desdibujadas, y en las que realizar reivindicaciones y proyectos en aislamiento es difícil que produzca un incremento de nuestra relevancia profesional. Nuestra debilidad de partida en número de investigadores y profesionales, recursos y contactos tiene que ser tenida en cuenta, tanto más cuanto que en todo el mundo desarrollado se progresa en la desregulación de las profesiones $y$, específicamente, del sector servicios, ante una realidad laboral orientada a la tarea y a proyectos que requieren una base crecientemente interdisciplinar. El camino lógico es la colaboración, sin perjuicio de que, gracias a la dinámica natural de especialización del trabajo se decanten también algunos nichos específicos.

En este sentido, la formación que se imparte en nuestras titulaciones, al combinar aspectos, perspectivas y metodologías humanísticas, de la ciencia social y técnicas, constituye - si se organiza adecuadamente y se consigue reclutar alumnos con capacidades suficientes - una buena base para formar a personas capaces de trabajar en esos equipos interdisciplinares y aun liderarlos.

Pero es que, además, el potencial interdisciplinar de la información y la documentación es tan grande, en realidad, como el número de disciplinas científicas existentes, como es bien sabido. En algunos casos, como ocurre con las ciencias de la comunicación, la colaboración está muy bien establecida. En otros casos, buenas perspectivas a priori han fracasado por el compromiso limitado de los profesores o la falta de un auténtico equipo de trabajo interdisciplinar. Sin embargo, hay muchas experiencias de éxito en este tipo 
de asignaturas auténticamente interdisciplinares, como nos demuestra el caso de la asignatura de documentación aplicada al marketing de la Universitat Autònoma de Barcelona, entre otros muchos que no son publicados (González-Quesada, 2011).

\section{Cuidar la marca y nuestros públicos objetivos, resi- tuando al estudiante como cliente principal}

Un tercer reto importante es consolidar una marca clara y potente, que es un problema que ha sido notado por muchos especialistas y se arrastra casi desde el inicio de la disciplina. De cara al conjunto de la sociedad y de la comunidad científica, el tema de la marca ha transido entre la acritud y la broma, desde que Javier Lasso de la Vega mostrara con orgullo su cátedra en "Bibliotecomanía", hasta el tira y afloja sobre la utilización del término información en las ciencias de la comunicación o el de la documentación - ya resuelto, al elegir los comunicólogos el de comunicación-, pasando por la etimología de informática como ciencia de la información o información automática y la confusión que se veía en este hecho. Ahora el término información está firmemente asentado en primera posición en el título de los estudios de grado y en el nombre de los centros. El problema ahora es que la información lo abarca todo; y que, por tanto, todas las disciplinas - desde la física hasta la economía, pasando por la biología - tienen subdisciplinas "informacionales" o incluso se redefinen como tales. La información está convirtiéndose en un concepto tan abarcante como el de la globalización, que quizá le esté empezando a quedar grande a las modestas aunque importantes tareas que realmente realizamos.

Es verdad que el término Biblioteconomía y Documentación presentaba muchos problemas para categorizar a nuestro estudios, pero al menos era reconocido por los estudiantes de enseñanzas medias de humanidades como una salida profesional y, por tanto, como una carrera a la que dedicarse. Por otra parte, el término Información y Documentación es más abarcador e incorpora sin ambages la revolución de internet, pero no conecta - o al menos no lo hace todavíacon el antiguo público de estudiantes de humanidades. Es más, es posible que los títulos de las asignaturas incluso espanten a nuestros clientes tradicionales, pues aparecen claramente inscritos en los campos de la tecnología y la gestión.

En este sentido hemos de aclararnos pronto sobre si queremos estudiantes de humanidades, de sociales, de tecnología o de cualquier cosa, en qué medida, y, sobre todo, cómo arbitrar el tránsito sin estrellarnos nosotros ni sacrificarlos a ellos. En cualquier caso, es necesario detectar los grupos de estudiantes a los que queremos y podemos llegar, y comunicarles adecuadamente los estudios; y no olvidar buscar a aquellos que realmente nos necesitan, pues sin estudiantes ningún estudio tiene futuro. Probablemente, el mundo académico español de la Biblioteconomía y la Documentación ha estado muy centrado en la imagen que daba a la academia y a la profesión, y en el reconocimiento que obtenía de estos importantes socios, pero estos últimos años nos han demostrado que los estudiantes son igualmente importantes y que no han sido tenidos en cuenta suficientemente.

\section{Arbitrar un observatorio permanente que permita programar las enseñanzas desde las necesidades del mercado de trabajo y de los estudiantes}

Pero una marca tiene que estar ligada a realidades tangibles; si no, la fascinación dará paso sin remedio al aborrecimiento. Pues, aunque hayamos detectado nuestros clientes $y$ tengamos una buena marca y un buen discurso publicitario, de nada sirve si nuestros clientes no quedan satisfechos. $Y$ en nuestro caso eso significa que, gracias a los estudios que han cursado, podrán comenzar una buena carrera profesional, mantener su puesto de trabajo, progresar, sentirse útiles a la sociedad y valorados por su entorno, y tener al cabo de los años una buena posición social y, por qué no, unos ingresos notables. En definitiva, es necesario facilitar una buena educación ligada a las necesidades del mercado de trabajo que efectivamente proporcione empleos a la altura de lo esperado por los estudiantes, y en definitiva que su inversión en tiempo, dinero y esfuerzo obtenga un retorno razonable a sus expectativas. Esto es un tema grave, porque si queremos fichar a estudiantes capaces de hacer avanzar la aplicación, la investigación y la docencia en el área, y, por tanto, reclutar buenos estudiantes y motivar y hacer crecer a los que no se dedican tanto, habrá que demostrarles que merece la pena.

\section{La impresión que producen los estudios de información y documentación es que hay que enseñarlo todo ya}

Demostrar a los estudiantes que merece la pena estudiar información y documentación requiere investigaciones sistemáticas "basadas en la evidencia”. En esta dirección -imprescindible para no guiarse tan sólo por la opinión o las experiencias limitadas - es necesario dar un paso más y conseguir que los investigadores y gestores del área se organicen para crear un observatorio de empleo y formación estable, permanente y comprensivo, en la línea de los esfuerzos que se han realizado en torno a ThinkEPI, Fesabid, Sedic y algunos otros foros profesionales importantes. En cualquier caso, hacen falta como mínimo datos adelantados tanto de empleo como de ingreso, y eso sólo lo puede conseguir un observatorio interuniversitario, pues hace falta recopilar datos en cada universidad, y hacer estudios del mercado de trabajo locales. Igualmente, como señala Tejada-Artigas (2013), resulta fundamental abordar el tema de la permanencia y la tasa de abandono, muy ligada a la gestión de las expectativas de los estudiantes, aspecto sobre el que todavía no hay estudios sistemáticos.

El observatorio no debe quedarse en ofrecer sólo cifras de tendencias, sino intentar un dimensionamiento de la oferta de empleo, en la línea del estudio que intenté hace cinco años (García-Marco, 2008). En él, basándome en los estudios de Moreiro-González, Moscoso y Repiso (1995), Tejada-Artigas y Moreiro-González (2003), Borrego, Comalat y Estivill (2004); Moreiro-González, Tejada-Artigas et al., 2008) que apoyan que el empleo estatal se sitúa entre el 35 y el $40 \%$ del total, ofrecía la cifra de puestos de em- 
pleo de calidad alrededor de los 667 y los 762 anuales. Estudios de este tipo permitirían realizar una aproximación al número de estudios y titulaciones deseables desde el punto de vista de la demanda de trabajadores, y no ofrecer titulaciones y puestos por el número de profesores disponibles o por la demanda de los alumnos de secundaria, criterios que, aunque deben ser tenidos en cuenta, pueden terminar frustrando las expectativas laborales de los estudiantes.

\section{Articular adecuadamente los niveles de formación con realismo y en el marco de una formación a lo lar- go de la vida}

En quinto lugar, y de nuevo pensando en los estudiantes, es urgente reconstruir los currículos para que sirvan de verdad de puente entre la realidad de los estudiantes que entran en nuestras aulas y la de las competencias profesionales que deben adquirir para desempeñarse correctamente. Los estudios actuales parecen en algunos casos un inmenso cajón de sastre que agrupa cuestiones tecnológicas, técnicas, de gestión, humanísticas y sociales con una gran ambición, pero con muchos solapamientos y huecos, y una gran pérdida de eficiencia educacional.

Además, los planes de estudio dispersos abocan a la frustración, pues es imposible enseñar bien sobre tantas cosas en tan poco tiempo y alcanzar unos resultados aceptables. De hecho, el grado actual tal y como emerge del Libro blanco de la titulación dedica menos tiempo a cada vez más cuestiones técnicas - ya no son sólo la catalogación, la indización y la clasificación, sino el marketing en las redes sociales o la administración de gestores de contenido- e intenta formar en materias de gestión con la ambición de una titulación en administración de empresas. Es imposible enseñar tanto y hacerlo bien, de manera que el alumno alcance competencias sólidas y demostrables en el mercado de trabajo, frente a otros profesionales que se forman en algunos de esos aspectos de forma más específica. Lo lógico sería asegurar mejor las competencias nucleares que les proporcionan empleo y renunciar a otras mejor servidas por otros expertos, incluso colaborando con otros departamentos para facilitar la formación en las competencias interuniversitarias básicas.

Cada vez está más establecido el concepto de formación a lo largo de la vida. Sin embargo, la impresión que producen los estudios de información y documentación es que hay que enseñarlo todo ya: a hacer el trabajo técnico, a gestionar unidades y servicios de información, y a desarrollar actividades especializadas objeto de multitud de asignaturas optativas, sin haber todavía desempeñado una profesión relacionada. El grado debería centrarse en las competencias generales y nucleares, y en adquirir buenas capacidades técnicas de base, y el nivel de master debería dedicarse a la administración - no todos van a ser administradores - y a las actividades de nicho y especializadas. $Y$, aunque esto no depende de nosotros, creo que ayudaría a este objetivo que el grado volviera a ser de tres años y el master de dos.

En cualquier caso (García-Marco, 2007), es necesario articular un nuevo modelo curricular con una clara división entre grado generalista y posgrados especializados. El grado se dedicaría a afianzar las competencias genéricas (cultura general, idiomas, escribir, presentar, etc.), adquirir competencias específicas instrumentales en el campo del análisis de la información (textual, visual, estadística, bibliográfica, archivística, etc.), las tecnologías de la información y comunicación, la programación, el trabajo en equipo y con los clientes y proveedores, la recuperación de información, y una perspectiva completa del mundo de la información actual desde su contexto general hasta su historia, paradigmas y modelos principales.

El nivel de posgrado debería preparar en masters especializados para funciones de nivel directivo, para la investigación, la enseñanza universitaria, y, notablemente, para los nichos de empleo que requieren preparación muy específica, y una gran dedicación: catalogación de documentos, referencia, gestión de registros, documentaciones especializadas (en conjunción con las respectivas especializaciones), administración de sistemas de gestión de contenidos, bibliometría y cienciometría, etc.

No es posible enseñar y aprender todo a la vez, ni siquiera en cinco cursos. Por ello, es obligación de los responsables académicos y de los representantes profesionales y de la sociedad que los estudios se organicen adecuadamente. Tampoco resulta ya una perspectiva honesta destinar los contenidos digitales al nivel de master y orillarlos en el grado: Como defenderemos después, la tecnología debe permear totalmente las enseñanzas. El tiempo de la "documentación digital" ha pasado, porque estamos ya entrando en un entorno mayoritariamente digital, y los masters deben dedicarse a otras especializaciones.

La situación ideal sería que se detectaran las diferentes especializaciones de master y el tamaño de la demanda de empleo existente; y, a partir de esta información, se organizara la comunidad universitaria española para dividirse el trabajo entre las diferentes universidades, contando cada una de ellas con los mejores recursos humanos disponibles, con independencia de dónde estuvieran. Esta solución requeriría también apoyo del Estado, para financiar los desplazamientos de los especialistas. Abordar de una manera inteligente y concertada la oferta de masters es una tarea tanto más necesaria, cuanto que si se consolida el umbral de los cincuenta estudiantes de nuevo ingreso como criterio para mantener los grados, será necesario reorientar la carga docente excedentaria a masters, formación transversal y permanente. Dentro de la segunda línea de acción, la experiencia de la Universidad Carlos III de Madrid en la reorientación de parte de la carga docente hacia asignaturas transversales en coordinación con la biblioteca de la universidad es muy interesante por su alcance estratégico y está bien documentada (Hernández-Pérez et al., 2011). Hay otras experiencias más reducidas por el número de asignaturas implicadas, pero también de gran interés (Jiménez-López, 2011).

Reconozco que, en este sentido, la situación española es especialmente difícil de cara a la concertación, pues ni siquiera existe una organización nacional y unas conferencias periódicas en las que intentar ponerse de acuerdo -a diferencia de lo que ocurre con nuestros hermanos brasileños, que tienen foros más desarrollados, especialmente a nivel de postgrado; y el panorama nacional está fraccionado en 
numerosos foros regionales, coordinados eso sí hasta cierto punto dentro de la federación Fesabid. Sin embargo, es también cierto que en los tres últimos años, el panorama español en cuanto a títulos de master oficiales ha empezado a diversificarse notablemente, lo cual hace pensar que la auto-organización también puede funcionar de forma espontánea si no es posible el diseño inteligente y concertado. Por otra parte, en el nivel de dirección de centros y departamentos se cuenta con un excelente instrumento de conversación y coordinación, a saber, la Red Universitaria de Información y Documentación (RUID), que se constituyó a raíz del trabajo realizado con el Libro blanco. Ciertamente, esta organización adolece todavía, a diferencia de lo que ocurre en Brasil o en el movimiento ischool, de la falta de instrumentos para la participación abierta, no meramente representada, de los profesores de los claustros. En este sentido, la experiencia de nuestros compañeros del Mercosur puede ofrecer un buen marco de referencia (Oliveira; Guimarães, 2004).

\section{Reconstruir y perseguir la interdisciplinariedad en el diseño de los estudios}

A caballo entre el problema del perfil de los estudiantes de ingreso y la organización de las titulaciones de salida, sigue presente el debate de si es posible formar a cualquier estudiante para el conjunto de salidas profesionales que se califican bajo el paraguas de la información y la documentación.

Es incuestionable que cualquier titulado competente en Información y Documentación puede desempeñarse aceptablemente en casi cualquier campo de especialización; pero también es cierto que no dará la talla de un especialista temático con formación equivalente en nuestro campo. Muchas profesiones de la información son mixtas: en la biblioteca escolar y la alfabetización informacional se combinan competencias de la pedagogía y la biblioteconomía; en las bibliotecas universitarias y especializadas, los mejores referencistas son también especialistas temáticos; en el archivo histórico son necesarias las competencias en paleografía y diplomática; el bibliotecario de sistemas de información geográfica debe tener una buena formación en geografía y en estas herramientas; en el museo, en arqueología o arte en los aspectos culturales implicados..

Este problema se puede abordar de forma razonable a través de alianzas para ofrecer itinerarios compartidos, complementarios y alternativos, dobles titulaciones, enseñanzas de grado y de master, minors and majors, y otras soluciones comparables. Estas alianzas favorecerían a ambas partes.

Creo que, contagiada del movimiento de especialización de la universidad española, que ha abocado a una fuerte endogamia en la organización de muchas titulaciones, la biblioteconomía-documentación académica se ha cerrado mucho en sí misma y necesita abrirse, establecer alianzas, invitar a especialistas de otras disciplinas, ofrecer transversales y cursos especializados en otras titulaciones... Mucho es el camino que se está realizando, especialmente en estos últimos años, pero todavía es más el que hay que recorrer. La endogamia conduce en las sociedades humanas al aislamiento, la infertilidad e incluso a problemas de salud física y mental; lo que pasa en el ámbito académico es sólo un caso concreto de esta ley general. Se trata de dar y tomar; de abrirse y participar.

\section{Modular la formación tecnológica de acuerdo con los cambios sociales y el perfil del alumnado}

Una fortaleza importante del cuerpo profesional y académico es la rapidez y devoción con la que ha asumido los nuevos dispositivos, las redes sociales, los gestores de contenido y las plataformas docentes, lo que le coloca en una posición muy buena para abordar la educación a distancia y semipresencial, que, sin duda, ofrece un gran potencial para llegar a una demanda mayor.

Sin embargo, sigue siendo necesario avanzar en el desarrollo de un modelo de enseñanza de las tecnologías que sea realmente eficaz. Es necesario terminar de forma definitiva el "desencuentro" (Moscoso, 2000) entre las disciplinas clásicas de la información y la documentación y las tecnologías de la información y la comunicación, y potenciar la formación técnica especializada (Martínez-Méndez, 1997). La enseñanza de las tecnologías debe ser transversal y todas las asignaturas tienen que verse implicadas en ella de forma organizada - evitando solapamientos y lagunas, pero también asegurando la suficiente práctica- de manera que los estudiantes lleguen a ser usuarios avanzados y avezados. Por supuesto, hay que enseñar con la última tecnología disponible, evitando a los estudiantes el bochorno de estar perdiendo el tiempo con herramientas muy por debajo de las que manejan en casa o en sus prácticas en centros profesionales. Finalmente, los estudiantes no tienen por que ser ingenieros informáticos, pero se les debe formar para que sean capaces de entenderse con los ingenieros, en particular en lo que se refiere al diseño de bases de datos, los lenguajes de modelado (unified modelling language, $U M L$ ) y, obviamente, los protocolos y formatos de internet; y ello alcanzando un conocimiento operativo, no solamente teórico. Finalmente, se deben ofrecer itinerarios específicos para los estudiantes que se quieran dedicar a la archivística o biblioteconomía de sistemas, y a la administración de gestores de contenidos, probablemente a nivel de posgrado.

La rapidez en asumir los nuevos dispositivos, las redes sociales, los gestores de contenido y las plataformas docentes, nos ha colocado en una posición muy buena para abordar la educación a distancia y semipresencial

\section{Cuidar la calidad operativa y abordar los métodos educativos desde la evidencia}

Aunque no nos vamos a extender en ello, es obvio que una condición muy importante del éxito de los estudios es la calidad del proceso educativo: las infraestructuras docentes -aulas, plataformas, laboratorios, biblioteca...-, la interacción en las aulas - preparación, gestión de la energía y los tiempos, disciplina, rigor y amabilidad... - y el acompa- 


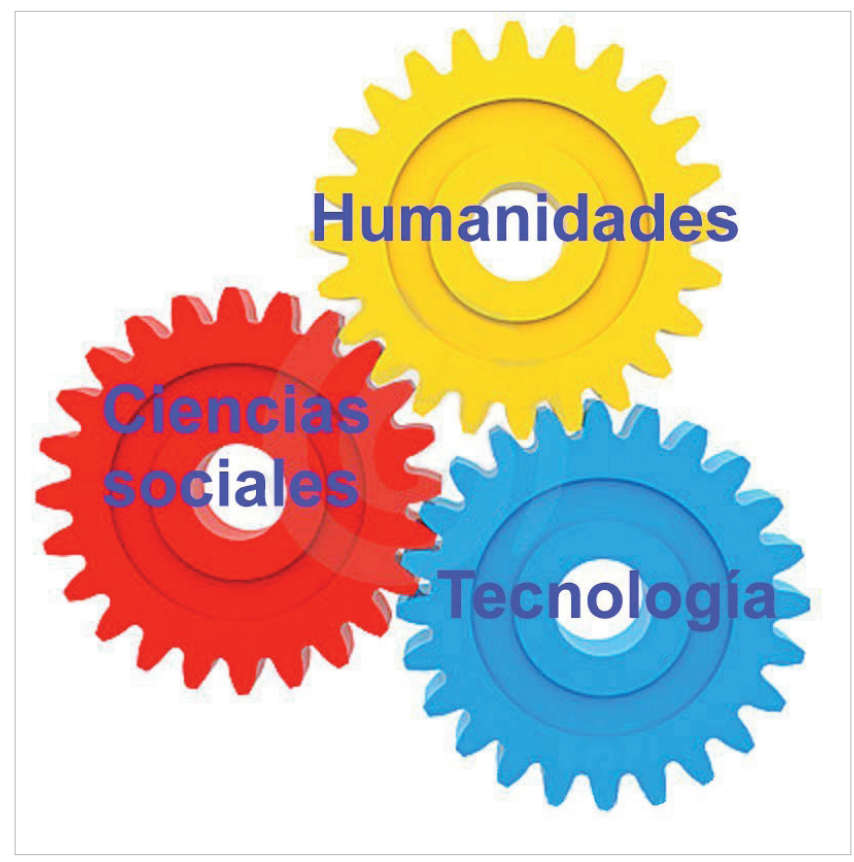

ñamiento de los estudiantes - tutorías, servicios de información, apoyo e inserción laboral...-. Si esto no se asegura, el edificio fallará por la base: los estudiantes percibirán un doble lenguaje entre lo que se dice y lo que se hace, y no se sentirán tratados con la dignidad adecuada. Ciertamente, las universidades y los profesores están haciendo una labor importante en esta dirección desarrollando infraestructuras y programas de apoyo, implementando sistemas de garantía de las titulaciones y los cursos, nombrando coordinadores de titulación que lideren el proceso, etc. Es necesario que los centros españoles compartan y sistematicen esta rica experiencia que se está acumulando entre ellos y con el resto del mundo.

Ahora bien, no sólo el diseño de los programas debe estar basado en la evidencia, sino el funcionamiento de las asignaturas. Una vez que el crédito basado en el trabajo del estudiante ha sido establecido como unidad de cuenta y que los objetivos se establecen en forma de competencias, es posible iniciar una investigación educativa digna de tal nombre y apoyada en datos empíricos. Es posible ver si diferentes métodos de enseñanza consiguen en el tiempo tasado mejores resultados en el desarrollo de competencias dadas unas condiciones previas constantes, y evaluar si los tiempos previstos son excesivos, razonables y parcos; $y$, entonces, sí, generalizar los hallazgos a otros contextos. La innovación educativa no puede basarse sólo en intuiciones, hay que dar el paso hacia la experimentación, la medida, el rigor y la sistematicidad.

\section{Epílogo: la inevitabilidad de lo global}

Vivimos un cambio de época y es lógico que la enseñanza de la información y la documentación se vea afectada tanto en el ámbito internacional como en el español. Las últimas décadas han culminado en una economía mundial profundamente entretejida por la división del trabajo y los flujos comerciales y financieros; una enorme movilidad de la población, los productos y las ideas; y una red mundial de intercambio de información que da soporte a todos estos flujos, potenciada recientemente por las tecnologías sociales, y cuyas deficiencias, resultado de su espectacular crecimiento, empiezan a ser abordadas con nuevas iniciativas, como la web semántica. Esta nueva oleada de la globalización es una realidad insoslayable, y constituye a la vez una amenaza y una oportunidad.

En el lado de las sombras, las incertidumbres no sólo amenazan la definición del campo profesional y disciplinar, como hemos analizado en detalle en las páginas anteriores, sino a la propia industria educativa. La globalización no sólo está cambiando la economía y la sociedad, sino que va a tener un impacto muy grande en la enseñanza y el aprendizaje. Durante la segunda mitad del siglo XX el mundo ha contemplado un enorme crecimiento del sistema universitario, apoyado por los gobiernos y las familias; pero, a la vista de las nuevas políticas, parece que los estados consideran terminado el trabajo de promoverlas. Se vislumbra a medio plazo un periodo de desestatalización de la enseñanza superior, en el que la competencia no se situará a nivel local o nacional, sino global. Las universidades públicas serán convertidas en organismos que tendrán que buscar la autofinanciación y competir entre ellas y con sus pares privados por los alumnos y los clientes. Y esa pelea se librará en el ámbito global, no en el local, que es el que preocupa todavía a los agentes sociales, en particular a los sindicatos. El surgimiento de los cursos masivos en línea (moocs) apunta claramente por donde pueden ir las cosas: una división del trabajo muy fuerte entre las universidades - posiblemente, más bien redes de centros de excelencia- que generan contenidos científicos y educativos, y aquellas que se ocuparán del servicio de proximidad, o, si se quiere, de la atención personal a los estudiantes. En este entorno, la enseñanza presencial de baja calidad sufrirá la enorme presión de los gigantes de la acreditación, que crearán programas de formación masiva en línea como extensión de su negocio. Los centros que pierdan alumnos perderán también profesores y títulos, y al final las disciplinas en cuestión quedarán minimizadas.

$\mathrm{Y}$, sin embargo, a pesar de las amenazas, en este escenario de inevitabilidad de la globalización y de creciente integración mundial se desarrolla, en medio de tensiones y conflictos, el nuevo mundo de la información y la documentación al que tenemos que orientar nuestros esfuerzos, ayudando a preservar las libertades y las identidades compartidas.

Nuestra misión es colaborar para que la nueva sociedad global que está emergiendo pueda ser administrada mejor; y podemos contribuir en al menos dos direcciones muy claras. Por un lado - hacia el lado de la demanda-, ayudando a comunicar e integrar el sistema, facilitando la comunicación abierta y respetuosa entre personas y grupos humanos que favorezca el intercambio económico, social y cultural pacífico y productivo, para que surja lo nuevo. Por el otro - desde el lado de la oferta-, ayudando a preservar los registros de conocimiento y de la identidad en una época de turbulencias económicas, sociales, políticas y culturales, para que nada bueno se pierda.

En este sentido, el reto de la información como disciplina y como carrera académica y profesional es contribuir a la evolución exitosa de la red de información que está sustentan- 
do una sociedad crecientemente compleja - al modo en el que en el orden fisiológico los organismos más complejos y adaptivos requieren también sistemas nerviosos más evolucionados (García-Marco, 1995e) - , bajo los valores clásicos de verdad, actualidad, servicio, adecuación y oportunidad.

La tecnología es una parte fundamental de este proyecto, pero la comprensión de los problemas y entornos humanos es un aspecto aún más central. El ámbito de la información y la documentación sigue siendo, en este sentido, la intersección entre humanidades, ciencias sociales (procesos) y tecnología; y creo que sólo un adecuado e integrado balance entre las tres ruedas producirá unos estudios que realmente mantengan y desarrollen su nicho dentro de la ecología de las ciencias y las profesiones.

El proceso de cambio que estamos viviendo empezó con una fase de expansión que terminó hace un lustro, y ahora estamos en otra de contracción, que está suponiendo una fuerte reconversión del sector. En nuestras manos está intentar contribuir a que la poda se realice de la forma más inteligente posible, y redunde en una consolidación y un renacimiento; o que se deje al -en nuestro país - joven árbol de la enseñanza y la investigación en información y documentación al arbitrio de los elementos, aumentando las posibilidades de que se produzcan daños irreparables y se pierdan décadas de trabajo invertidas en el desarrollo de unas disciplinas universitarias dedicadas a la gestión de la información y a la preservación de la memoria de la sociedad, las instituciones y los individuos.

\section{Notas}

1. La bibliografía sobre el tema es ya grande. Para los primeros momentos es una buena referencia el artículo de Luis García-Ejarque (1974), para el tránsito a las escuelas el de Josefina Mateu (1981) y, por supuesto, la gran revisión de Luis García-Ejarque de 1993; para la situación a comienzos de los noventa la tesis y el artículo de Ernest Abadal (1992, 3), con una perspectiva netamente universitaria; y para el despegue del segundo y tercer ciclo y los atisbos de la crisis su artículo con Concepció Miralpeix (Abadal; Miralpeix, 1999). Eulàlia Fuentes-Pujol, Àngels Jiménez-López y Alfons González-Quesada (2001) realizaron también una excelente revisión de la historia del área en el siglo pasado, que integra, además, los aspectos relacionados con la investigación.

2. Por otra parte, estamos a la espera de datos sobre los nuevos masters oficiales, que permitan evaluar la situación al respecto, especialmente tras la amenaza que supone a la matriculación de nuevos estudiantes la reciente subida de tasas universitarias.

3. Una revisión desde el punto de vista español en GarcíaMarco (2009).

4. Los estudios han sido fundamentalmente de tres tipos: datos sobre empleo público o privado proporcionados por agencias gubernamentales o privadas, seguimiento de la inserción y el progreso laboral a través de encuestas a egresados o asociados y el análisis de las ofertas de trabajo. En particular, destaca el esfuerzo realizado en la segunda línea de investigación (Moreiro-González; Moscoso et al., 1995;
Muñoz-Escolá, 1997; Moreiro-González, 1999; MoreiroGonzález, 2001; Tejada-Artigas, 2002; Tejada-Artigas; Moreiro-González, 2003; Borrego; Comalat et al., 2004; Domingodel-Valle; Ubieto-Artur, 2008; Abadal; Borrego; Serra, 2013). También se han realizado varios estudios de ofertas de trabajo, especialmente las publicadas en los servicios InfoDoc y RecBib (Montes, 1995; Alonso-Arévalo; Vázquez-Vázquez, 2000; Marquina, 2009) - también realizados en otros países, como Brasil (Vieira-da-Cunha, 2009; Fujino; Ginez-deLara, 2007) - y recientemente en los servicios de empleo universitarios (Abadal et al., 2003). José-Antonio MoreiroGonzález y sus colaboradores (2009) han abierto una línea de trabajo experimental muy prometedora para el seguimiento y análisis automático de ofertas de trabajo. También se han realizado estudios importante con información recabada por las asociaciones profesionales entre sus asociados, como la encuesta Sedic 2006 (Tejada-Artigas; Rodríguez-Yunta, 2007) o el estudio Fesabid (Merlo-Vega et al., 2011). Finalmente, se han manejado como indicador los convenios de prácticas y colaboración (Comalat et al., 2003).

5. El panorama del empleo no es el mismo, no obstante, en las metrópolis de nuestro país, como Madrid o Barcelona, en las que existe una economía terciaria y aun cuaternaria potente, con una presencia importante del sector privado, que demanda los servicios de los profesionales de la información y la documentación, que en las ciudades medianas, en las que está ligado a la administración, la educación y los servicios culturales, en su mayor parte dependientes del estado.

\section{Referencias}

Abadal, Ernest (1992). Orígens i desenvolupament de la informació i documentació a l'Estat espanyol: el problema de la denominació. Barcelona: Universitat Autònoma de Barcelona. ISBN: 8479293144

Abadal, Ernest (1993). "La formación en biblioteconomía y documentación en España”. Documentación de las ciencias de la información, v. 16, pp. 9-46.

http://revistas.ucm.es/index.php/DCIN/article/view/ DCIN9393110009A/20105

Abadal, Ernest; Miralpeix, Concepció (1999). "La enseñanza de la Biblioteconomía y la Documentación en la universidad española a finales de los noventa". BiD: Textos universitaris de biblioteconomia i documentació, n. 2.

http://bid.ub.edu/02abamir.htm

Abadal, Ernest; Borrego, Àngel; Serra-Pérez, Rafael (2012). "Mercado laboral de profesionales de la información: evolución de la oferta y de los perfiles ocupacionales". BiD: Textos universitaris de biblioteconomía y documentació, diciembre, n. 29.

http://www.ub.edu/bid/29/abadal2.htm

Agencia Nacional de Evaluación de la Calidad y Acreditación (2004). Libro blanco: Título de grado en Información y Documentación. Madrid: Aneca.

http://www.aneca.es/var/media/150424/libroblanco_ jun05_documentacion.pdf

Alonso-Arévalo, Julio; Vázquez-Vázquez, Marta (2000). "Características del comportamiento del mercado de traba- 
jo en Biblioteconomía, Archivística y Documentación: bienio 98/99". Anales de documentación, n. 3, pp. 9-24. http://revistas.um.es/analesdoc/article/view/2531

Arguimbau, Llorenç; Ribera, Marc; Fuentes-Pujol, Maria-Eulàlia (2011). "La Web 2.0 en la gestión y la comunicación de información: una experiencia docente”. Scire, v. 17, n. 2, pp. 39-48.

http://www.ibersid.eu/ojs/index.php/scire/article/ view/3929/3627

Borrego, Àngel; Comalat, Maite et al. (2004). “Inserció laboral dels titulats en Biblioteconomia i Documentació per la Universitat de Barcelona". BiD: Textos universitaris de biblioteconomia i documentació, juny, n. 12.

http://www2.ub.es/bid/consulta_articulos. php?fichero=12borreg.htm

Comalat, Maite; Espelt, Constança; Rubió, Anna (2003). "Nous jaciments laborals per a diplomats: anàlisi dels convenis de cooperació educativa de la Facultat de Biblioteconomia i Documentació (UB), 1998-2002". Ítem, gen.-abr., n. 33, pp. 71-83.

http://www.raco.cat/index.php/Item/article/view/22589/22423

Cronin, Blaise (2005). "An I-dentity crisis? The information schools movement". International journal of information management, v. 25, pp. 363-365.

http://dx.doi.org/10.1016/j.ijinfomgt.2005.04.007

Cronin, Blaise (2012). "The waxing and waning of a field: reflections on information studies education". Information research, v. 17, n. 3, paper 529.

http://InformationR.net/ir/17-3/paper529.html

De-la-Moneda-Corrochano, Mercedes (2012) "Las cifras de la enseñanza universitaria en documentación en España: 2010". Anuario ThinkEPI, v. 6. pp. 13-30.

http://ec3noticias.blogspot.com.es/2010/07/las-cifras-dela-ensenanza.html

Delgado-López-Cózar, Emilio (2002). La investigación en biblioteconomía y documentación. Gijón: Trea, 2002. ISBN: 8497040414

Delgado-López-Cózar, Emilio (2003). “Las cifras de la documentación en España: 2002". El profesional de la información, v. 12, n. 5, pp. 344-367.

Delgado-López-Cózar, Emilio (2008). “El ocaso de las enseñanzas universitarias de Documentación en España". Anuario ThinkEPI, pp. 126-129.

https://listserv.rediris.es/cgi-bin/wa?A2=IWETELO509;97c52bd3.0710c

Delgado-López-Cózar, Emilio (2007). “Las cifras de la infraestructura, profesión y educación documental en España: 2005". Anuario ThinkEPI, v. 1, pp. 207-217.

Delgado-López-Cózar, Emilio; De-la-Moneda-Corrochano, Mercedes (2008). "Las cifras de la enseñanza universitaria en Documentación en España: 2006". El profesional de la información, jul.-ag., v. 17, n. 4, pp. 428-434.

http://dx.doi.org/10.3145/epi.2008.jul.10

Domingo-del-Valle, María; Ubieto-Artur, María-Isabel (2008). "Situación laboral de los diplomados en biblioteconomía y documentación por la Universidad de Zaragoza
(1992-2006)". El profesional de la información, v. 17, n. 6, pp. 648-656.

Estivill-Rius, Assumpció (2006). "Una mirada retrospectiva: de l'Escola Superior de Bibliotecàries a la Facultat de Biblioteconomia i Documentació (1915-2005)". BiD: textos universitaris de biblioteconomia i documentació, juny, n. 16. http://bid.ub.edu/16estivi.htm

European Council of Information Associations (1999). Euroguide LIS, The guide to competencies for European professionals in library and information services. London: Aslib.

European Council of Information Associations (2004). Euroguide LIS, The guide to competencies for European professionals in library and information services. Paris: ADBS Édition. http://www.certidoc.net/en/euref2-english.pdf

Faba-Pérez, Cristina; Rico-Collado, Francisco-Luis (2012). "Las competencias transversales en los títulos de biblioteconomía y documentación: ¿avance o retroceso?". Ibersid, v. 6, pp. 101-109.

http://www.ibersid.eu/ojs/index.php/ibersid/article/ view/3979/3685

Frías, José-Antonio; Travieso, Críspulo, eds. (2008). “Formación, investigación y mercado laboral en información y documentación en España y Portugal = Formação, investigação e mercado de trabalho em informação e documantação em Espanha e Portugal". En: Actas del III Encuentro ibérico de docentes e investigadores en información y documentación. Salamanca: Ediciones Universidad de Salamanca. ISBN: 9788474816549

Fuentes-Pujol, Maria-Eulàlia, ed. lit. (2011). “Competencias informacionales e innovación docente en la educación superior". Número monográfico de Scire. Zaragoza: Ibersid.

Fujino, Asa; Ginez-de-Lara, Marilda-Lopes et al. (2007). "Perfil profissional e competências de informação em Biblioteconomia e Documentação: pesquisa com egressos da ECA/USP: XXII CBBD, Brasília". Anais XXII CBBD. Brasil, Febab.

García-Ejarque, Luis (1974). "La formación profesional de los bibliotecarios en España". Boletín de la Anaba, v. 24, n. 3-4, pp. 3-11.

García-Ejarque, Luis (1993). La formación del bibliotecario en España: de la paleografía y la bibliografía a la biblioteconomía y la documentación. Madrid: Anabad. ISBN: 8488716095

García-Marco, Francisco-Javier (1995). “Hacia un modelo de intervención en procesos de transmisión del conocimiento". Scire: Representación y organización del conocimiento, jul.-dic., v. 1, n. 2 , pp. 105-138.

http://ibersid.eu/ojs/index.php/scire/article/view/1045/1027

García-Marco, Francisco-Javier (2010). “Las instituciones de la memoria ante el cambio digital: una propuesta sobre la articulación interdisciplinar de las ciencias de la documentación". Pliegos de Yuste: revista de cultura y pensamiento europeos, n. 11.

http://www.pliegosdeyuste.eu/n1112pliegos/pdfs/61-70.pdf

García-Marco, Francisco-Javier (2007). “Perspectivas sobre la enseñanza de posgrado en Ciencias de la Documentación 
en España". Ibersid, v. 1, pp. 291-302.

http://ibersid.eu/ojs/index.php/ibersid/article/ download/3320/3081

García-Marco, Francisco-Javier (2008). "La Biblioteconomía y la Documentación española en la encrucijada". Ibersid, v. 2, pp. 307-318.

http://ibersid.eu/ojs/index.php/ibersid/article/ download/2254/2015

García-Marco, Francisco-Javier (2009). "El movimiento ischools: posicionando los estudios de biblioteconomía y documentación en la era de la información". Anuario ThinkEPI, v. 3, pp. 95-99.

García-Marco, Francisco-Javier (2011a). “Promoviendo la integración de estudiantes de nuevo ingreso en el grado de Información y Documentación a través de asignaturas introductorias". Scire, v. 17, n. 2, pp. 63-80.

http://www.ibersid.eu/ojs/index.php/scire/article/ view/3926/3625

García-Marco, Francisco-Javier (2011b). "Libraries in the digital ecology: reflections and trends". The electronic library, v. 29, n. 3, pp. $105-120$.

http://dx.doi.org/10.1108/02640471111111460

García-Marco, Francisco-Javier (2011c). "La revolución silenciosa: once tendencias de cambio en la ecología de la información". Ibersid, v. 5, pp. 13-21.

http://ibersid.eu/ojs/index.php/ibersid/article/view/3936

González-Quesada, Alfons; Molero-YII, Joan-Ramon (2011). “¿Hacia el docuketing? Una experiencia de colaboración docente en el grado de Publicidad y Relaciones Públicas de la Universitat Autònoma de Barcelona". Scire, v. 17, n. 2, pp. 81-85.

http://www.ibersid.eu/ojs/index.php/scire/article/view/3925

Hernández-Pérez, Tony; Pacios, Ana-Reyes; Vianello, Marina; Aguilera-Ortega, Raúl; Ramos-Gorospe, Mayte (2011). "La formación en alfabetización en información en las aulas universitarias: el caso de la UC3M". Scire, v. 17, n. 2, pp. 27-37. http://www.ibersid.eu/ojs/index.php/scire/article/view/3927

Jiménez-López, Maria-Àngels (2011). “El ejercicio de la docencia virtual en la educación universitaria: consideraciones prácticas basadas en la experiencia de una asignatura para la formación de competencias informacionales". Scire, v. 17, n. 2, pp. 49-62.

http://www.ibersid.eu/ojs/index.php/scire/article/view/3931

Marquina-Arenas, Julián (2009). “Perspectivas profesionales de los diplomados y licenciados en Biblioteconomía y Documentación". Rec-Bib: recursos bibliotecarios, abrilmayo, 2008.

http://eprints.rclis.org/bitstream/10760/13204/1/ Perspectivas_profesionales_ByD.pdf

Martínez-Comeche, Juan-Antonio, coord. (1997). Métodos didácticos en Biblioteconomía y Documentación: VI Jornadas Académicas organizadas por la Escuela Universitaria de Biblioteconomía y Documentación de la Universidad Complutense de Madrid, 10-11 de marzo de 1997. Madrid: Universidad Complutense. ISBN: 8474915732
Martínez-Méndez, Francisco-Javier (1997). “La formación en sistemas de información electrónica y nuevos documentos". Scire, v. 3, n. 2, pp. 11-30.

http://ibersid.eu/ojs/index.php/scire/article/view/1073

Mateu-Ibars, Josefina (1981). "Biblioteconomía en la universidad". Boletín de la Anabad, v. 31, n. 4, pp. 637-651. http://dialnet.unirioja.es/descarga/articulo/965302.pdf

Merlo-Vega, José-Antonio; Gómez-Hernández, José-Antonio; Hernández-Sánchez, Hilario (2011). Estudio Fesabid sobre los profesionales de la información: prospectiva de una profesión en constante evolución. Madrid: Fesabid.

http://eprints.rclis.org/handle/10760/18057

Montes-López, Evelio (1995). “El mercado de trabajo de los documentalistas en España: análisis de una muestras de ofertas de empleo, 1984-1994". Revista española de documentación científica, v. 18, n. 2, pp. 178-187.

http://dx.doi.org/10.3989/redc.1995.v18.i2.655

Morales-Sanabria, Carmen (2012). "Mapa de los estudios de información y documentación en España". Clip: Boletín de Sedic, octubre-diciembre, n. 66.

http://www.sedic.es/p_boletinclip66_panorama_imprimir.htm

Moreiro-González, José-Antonio (1999). Ajuste de los licenciados en documentación a la oferta de trabajo: observaciones hechas en la Universidad Carlos III de Madrid. Revista general de información y documentación, v. 9, n. 2, pp. 13-28. http://revistas.ucm.es/index.php/RGID/article/view/ RGID9999220013A/10563

Moreiro-González, José-Antonio (2001). “Figures on employability of Spanish library and information science graduates". Libri, v. 51, pp. 27-37.

http://dx.doi.org/10.3989/redc.2009.1.675

Moreiro-González, José-Antonio; Azcárate-Aguilar-Amat, Pilar et al. (2008). "Desarrollo profesional y opinión sobre la formación recibida de los titulados universitarios en información y documentación de las universidades públicas de Madrid, 2000-2005". El profesional de la información, mayojunio, v. 17, n. 3, pp. 261-272.

http://dx.doi.org/10.3145/epi.2008.may.02

Moreiro-González, José-Antonio; Moscoso, Purificación et al. (1995). "El mercado de trabajo de los diplomados españoles en biblioteconomía y documentación". Revista española de documentación científica, v. 18, n. 4, pp. 444-463.

http://redc.revistas.csic.es/index.php/redc/article/ view/640/715

Moreiro-González, José-Antonio; Sánchez-Cuadrado, Sonia et al. (2009). "Desarrollo de una aplicación ontológica para evaluar el mercado de trabajo español en Biblioteconomía y Documentación". Revista española de documentación científica, v. 32, n. 1.

http://dx.doi.org/10.3989/redc.2009.1.675

Moscoso, Purificación (2000). “Tecnologías y Documentación: veinticinco años de desencuentros en la enseñanza universitaria" . En: Congreso universitario de ciencias de la documentación. Teoría, historia y metodología de la documentación en España (1975-2000). I. 2000. Madrid: Univer- 
sidad Complutense, pp. 87-100.

Múnera-Torres, María-Teresa (2012). “Perfiles de formación bibliotecológica en algunas universidades de América del Sur". Scire, v. 6, pp. 95-100.

http://www.ibersid.eu/ojs/index.php/ibersid/article/ view/4036/3694

Muñoz-Escolá, Mercedes (1997). “Análisis de la situación laboral y de formación de los estudiantes y diplomados en Biblioteconomía y Documentación por la Universidad de Zaragoza". Revista general de información y documentación, v. 7, n. 1, pp. 329-344.

http://dialnet.unirioja.es/servlet/articulo?codigo $=169994 \&$ orden $=1$ \&info=link

Oliveira, Ely-Francina-Tannuri; Guimarães, José-AugustoChaves (2004). "Políticas de formación profesional en el área de información en el Mercosur". Scire, en.-jun., v. 10, n. 1, pp. 145-157.

http://www.ibersid.eu/ojs/index.php/scire/article/ view/1484/1462

Ortiz-Repiso, Virginia; Calzada-Prado, Javier; AportelaRodríguez, Ivett M. (2013). “¿Qué está pasando con los estudios universitarios de biblioteconomía y documentación en España?". El profesional de la información, septiembreoctubre, v. 22, n. 6, pp. 505-514.

http://dx.doi.org/10.3145/epi.2013.nov.02

Pinto-Molina, María (2011). “Los portales educativos como instrumentos innovadores para la formación en competencias informacionales de los estudiantes universitarios". Scire, v. 17, n. 2, pp. 13-14.

http://www.ibersid.eu/ojs/index.php/scire/article/view/3933

Fuentes-Pujol, Maria-Eulàlia; Jiménez-López, Maria-Àngels; González-Quesada, Alfons (2001). "La investigación y la literatura especializada en Información y Documentación: una revisión". Scire: representación y organización del conocimiento, v. 7, n. 2, pp. 11-38.

http://www.ibersid.eu/ojs/index.php/scire/article/view/1148

Saorín-Pérez, Tomás; De-Haro-San-Mateo, Verónica; Pastor-Sánchez, Juan-Antonio (2011). “Posibilidades de Wiki- pedia en la docencia universitaria: elaboración colaborativa de conocimiento". Ibersid, v. 5, pp. 89-97.

http://www.ibersid.eu/ojs/index.php/ibersid/article/view/3915

Segon seminari internacional de docència bibliotecària = Second international seminar on librarian education / [Organizado por la] Escola Universitària Jordi Rubio i Balaguer de Biblioteconomia i Documentació, 20-22 de desembre de 1990. Barcelona: Diputació, 1993. ISBN: 8477942544

Tejada-Artigas, Carlos (2002). Adecuación de los planes de estudio de la Diplomatura en Biblioteconomía y Documentación a las demandas del mercado de trabajo. El caso concreto del nuevo plan de estudios de la Escuela Universitaria de Biblioteconomía y Documentación de la Universidad Complutense de Madrid. Madrid, Universidad Carlos III de Madrid. Tesis doctoral.

http://hdl.handle.net/10016/11305

Tejada-Artigas, Carlos (2013). "Profesión y formación universitaria en 2012". Anuario ThinkEPI, v. 7, pp. 17-23.

Tejada-Artigas, Carlos; Moreiro-González, José Antonio (2003). "Mercado de trabajo en biblioteconomía y documentación: estudios sobre la inserción laboral de los titulados universitarios". El profesional de la información, enerofebrero, v. 12, n. 1, pp. 4-9.

http://dx.doi.org/10.1076/epri.12.1.4.19700

Tejada-Artigas, Carlos; Rodríguez-Yunta, Luis (2007). “Un acercamiento a la situación laboral y desarrollo profesional de los trabajadores de la información y documentación: la encuesta Sedic 2006" En: 10as Jornadas españolas de documentación, Santiago de Compostela, 9-11 de mayo de 2007. Santiago de Compostela: Fesabid.

http://eprints.rclis.org/9535

Varela-Prado, Carmen (2013). "El maestro bibliotecario como agente propulsor de la biblioteca escolar". Ibersid, v. 7, pp. 103-116.

Vieira-da-Cunha, Miriam (2009). "The information professional's profile: an analysis of Brazilian job vacancies on the internet". Information research, v. 14, n. 3, pp. 6-14. http://informationr.net/ir/14-3/paper407.html 